\title{
Closing the loop on the GABA shunt in plants: are GABA metabolism and signaling entwined?
}

\author{
Simon Michaeli ${ }^{\dagger}$ and Hillel Fromm* \\ Department of Molecular Biology and Ecology of Plants, Faculty of Life Sciences, Tel Aviv University, Tel Aviv, Israel
}

\section{OPEN ACCESS}

Edited by:

Giuseppe Forlani,

University of Ferrara, Italy

Reviewed by:

Vasileios Fotopoulos,

Cyprus University of Technology,

Cyprus

Wayne Snedden

Queen's University, Canada

*Correspondence: Hillel Fromm,

Department of Molecular Biology and Ecology of Plants, Faculty of Life Sciences, Tel Aviv University, Haim Levanon Street, Tel Aviv 69978,

Israel

hillelf@tauex.tau.ac.il

${ }^{\dagger}$ Present address:

Simon Michaeli,

Biochimie et Physiologie Moléculaire des Plantes, Institut de Biologie Intégrative des Plantes,

UMR5004 CNRS/INRA/UM2/SUPAgro,

2 Place Viala, 34060 Montpellier cedex 2, France

Specialty section:

This article was submitted to Plant Physiology,

a section of the journal Frontiers in Plant Science

Received: 28 March 2015 Accepted: 25 May 2015

Published: 09 June 2015

Citation:

Michaeli S and Fromm H (2015) Closing the loop on the GABA shunt in plants: are GABA metabolism

and signaling entwined?

Front. Plant Sci. 6:419.

doi: 10.3389/fp/s.2015.00419
$\gamma$-Aminobutyric acid (GABA) is a non-proteinogenic amino acid that is found in uniand multi-cellular organisms and is involved in many aspects of plant life cycle. GABA metabolism occurs by the action of evolutionary conserved enzymes that constitute the GABA shunt, bypassing two steps of the TCA cycle. The central position of GABA in the interface between plant carbon and nitrogen metabolism is well established. In parallel, there is evidence to support a role for GABA as a signaling molecule in plants. Here we cover some of the recent findings on GABA metabolism and signaling in plants and further suggest that the metabolic and signaling aspects of GABA may actually be inseparable.

Keywords: $\gamma$-Aminobutyric acid, GABA shunt, glutamate decarboxylase, tricarboxylic acids, Arabidopsis, stress

\section{GABA is Associated with Primary Nitrogen and Carbon Metabolism and is Tightly Linked to the TCA Cycle}

$\gamma$-Aminobutyric acid (GABA) is a four-carbon (C) non-proteinogenic amino acid (AA) that was first discovered in plants over half a century ago (Steward et al., 1949). GABA was later revealed in mammalian brain (Roberts and Frankel, 1950) and soon main interest in GABA shifted to animals when it was shown to play a major role in neurotransmission (Roberts et al., 1960). GABA has since been investigated in several organisms including bacteria, fungi, plants and animals (Bouché et al., 2003b). In both eukaryotes and bacteria GABA is a significant component of the free AA pool (Shelp et al., 1999) and the enzymes involved in GABA metabolism are conserved (Metzer and Halpern, 1990; Tillakaratne et al., 1995; Bown and Shelp, 1997; Kumar et al., 2000). Similar enzymes (e.g., glutamate decarboxylase) are found also in archaea, however their roles in GABA metabolism are questionable (Tomita et al., 2014). Interest in plant GABA increased mainly following observations of rapid elevation of its levels under abiotic stresses. Nevertheless, the roles of GABA under these conditions is not clear (Kinnersley and Turano, 2000; Fait et al., 2008). Recent combined genetics and physiological studies of the GABA shunt indicate that its function is required for proper growth in response to abiotic stresses such as low light (Michaeli et al., 2011) and salt (Renault et al., 2013).

$\gamma$-Aminobutyric acid is metabolized via a short pathway known as the GABA shunt (Figure 1), which bypasses two steps of the tricarboxylic acid cycle (TCAC). GABA is mainly produced by the irreversible reaction of the cytosolic enzyme glutamate decarboxylase (GAD; EC 4.1.1.15) that consumes a proton and releases $\mathrm{CO}_{2}$ (Baum et al., 1993; Fait et al., 2008). However, GABA synthesis may also occur via polyamine (putrescine and spermidine) degradation (Fait et al., 2008; Shelp et al., 2012a) and possibly by a non-enzymatic reaction from proline under oxidative stress (Signorelli et al., 2015). GABA catabolism occurs in the mitochondrial matrix of multicellular organisms by the action of GABA transaminase (GABA-T; EC 2.6.1.19) to produce succinic semi-aldehyde (SSA) with the possible participation of several amino acceptors such as $\alpha$-ketoglutarate (AKG), pyruvate or glyoxylate (Clark et al., 2009a; Shelp et al., 2012b). Subsequently, SSA is converted by another 


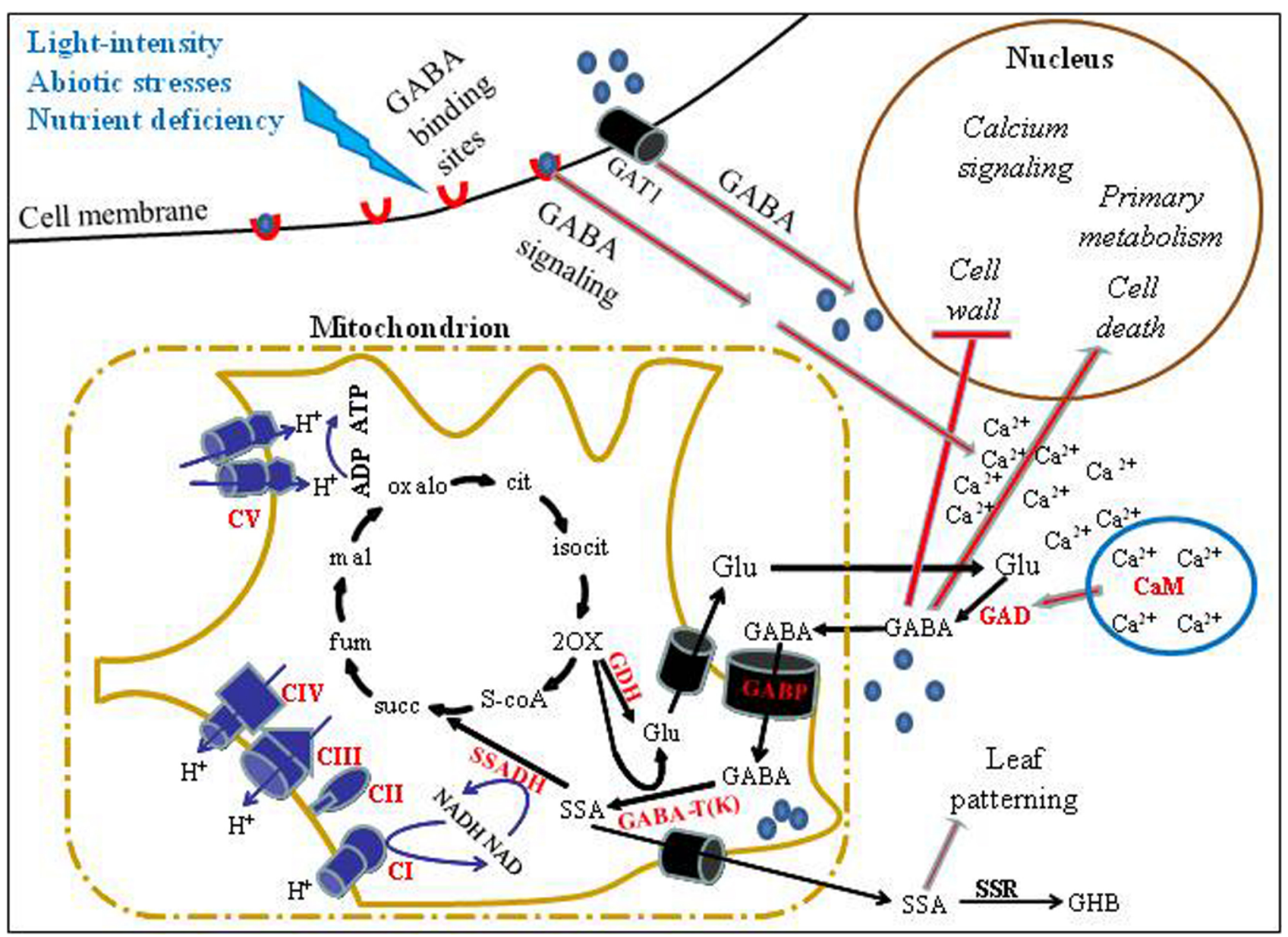

FIGURE 1 | A schematic model of GABA transport, metabolism and signaling in plant cells. External stimuli, such as abiotic stresses and light deficiency, regulate the expression of GABA shunt-associated genes. Such stimuli may further result in increased levels of GABA, enabling its attachment to cell-surface binding sites that generate transient $\mathrm{Ca}^{2+}$ increase and transport into cells via high affinity GABA transporters (e.g., GAT1; Meyer et al., 2006). Consequentially, GAD may be activated via a $\mathrm{Ca}^{2+} / \mathrm{CaM}$ complex (Baum et al., 1993). This increase in intracellular GABA may induce the expression of several signaling and metabolism-associated genes while repressing other genes such as genes associated with cell wall-modifications. Depending on the environmental conditions, a significant proportion of cytosolic GABA may enter mitochondria through the GABA permease, AtGABP (Michaeli et al., 2011), for catabolism by GABA-T and SSADH, resulting in succinate formation to feed the TCAC and mitochondrial ETC. Alternatively, the toxic intermediate, SSA, may be transported out of the mitochondrion to form GHBA via the enzyme SSR (GHBDH). We note that recently a tonoplast Glu/Asp/GABA exchanger in tomato fruit has been reported (Snowden et al., 2015), which is not included in the presented model. Enzyme names are in bold and red, whereas the reactions they perform are indicated as black arrows. Red-filled lines indicate a regulatory effect. Blue spheres denote GABA, red crescents denote GABA receptors. Abbreviations: GDH, Glutamate dehydrogenase; succ, succinate; fum, fumarate; Mal, malate; oxalo, oxaloacetate; cit, citrate; isocit, isocitrate; 2-OX, 2-oxoglutarate ( $\alpha$-ketoglutarate); Glu, glutamate; $\mathrm{Cl}, \mathrm{Cll}, \mathrm{CIII}, \mathrm{CIV}$, and CV, complexes I, II, III, IV and V of the mitochondrial ETC, Respectively. mitochondrial enzyme, SSA dehydrogenase (SSADH; EC 1.2.1.16) to succinate that acts both as an electron donor to the mitochondrial electron transport chain (ETC) and as a component of the TCAC (Bouché et al., 2003a; Shelp et al., $2012 b$ ). Alternatively, SSA can be converted to $\gamma$-hydroxybutyric acid (GHBA) through a GHB dehydrogenase (GHBDH) that was reported in animals and plants (Andriamampandry et al., 1998; Breitkreuz et al., 2003) and more recently in E. coli (Saito et al., 2009). Because AKG may serve as a precursor of glutamate and subsequently of GABA, this metabolic pathway may be viewed as bypassing two enzymatic steps of the TCAC (Figure 1), AKG dehydrogenase (AKGDH) and Succinyl Co-A ligase (SCOAL), thus termed the GABA shunt (Bown and Shelp, 1997).
Direct functional association of the GABA shunt and the TCAC was demonstrated in transgenic tomato plants with reduced activity of SCOAL (Studart-Guimaraes et al., 2007) and in potato slices treated with a specific chemical inhibitor of AKGDH (Araújo et al., 2008). Both enzymes are bypassed by the GABA shunt and in both cases elevated flux through the GABA shunt compensated for the lost activity of these TCAC enzymes. Reciprocally, mutants of the Arabidopsis GABP (mitochondrial GABA transporter) resulted in reduced uptake of GABA into mitochondria and increased TCAC activity (Michaeli et al., 2011). Much data accumulated regarding plant TCAC in illuminated leaves (Tcherkez et al., 2009; Sweetlove et al., 2010; Araújo et al., 2011a) where it seems to "lose" its classical cyclic metabolic form. 
Evidence suggests that citrate, stored from the TCAC activity of the previous night, is mainly shuttled for $\mathrm{N}$ assimilation (Tcherkez et al., 2009; Sweetlove et al., 2010). Interestingly, the GABA shunt, as one of the bridges between $\mathrm{N}$ and $\mathrm{C}$ metabolism, is significantly active in illuminated Xanthium strumarium (cocklebur) leaves as demonstrated by the high metabolic flux through it. On the other hand, a metabolic flux from AKG to succinate through the TCAC was almost undetectable (Tcherkez et al., 2009; Figure 1). In other words, the GABA shunt is apparently the major source for succinate in leaves at day time, contrary to the night-type heterotrophic plant metabolism where TCAC functions in its classical cyclic form (Sweetlove et al., 2010).

An interesting transcriptional co-response was demonstrated with Arabidopsis genes that encode the GABA shunt pathway (GAD2 and SSADH) and other primary $\mathrm{C}$ metabolism associated genes, providing further support for the association of GABA with primary $\mathrm{C}$ metabolism in plants at both the metabolome and transcriptome levels (Fait et al., 2008). It should be noted that the genes encoding the mitochondrial GABA permease, AtGABP and the GABA catabolic enzyme SSADH are also highly coexpressed in response to stress (Michaeli et al., 2011). Changes in the cellular distribution and quantity of GABA were shown also to affect levels of several AAs in different plant species (Baum et al., 1996; Michaeli et al., 2011; Deleu et al., 2013; Shimajiri et al., 2013a; Batushansky et al., 2014; Snowden et al., 2015) and even in seeds (Fait et al., 2011). As a molecule synthesized mainly from glutamate, yet intimately associated with the TCAC, GABA is continuously suggested to be an important component in the balance between $\mathrm{C}$ and nitrogen $(\mathrm{C}: \mathrm{N})$ pools of plant cells (Fait et al., 2008; Renault, 2013; Batushansky et al., 2014).

\section{Effects of GABA on Plant Development, Organ Patterning, Interaction with Pathogens and Fertility}

A signaling role for GABA in plants is continuously suggested and discussed (Bouché et al., 2003b; Bouché and Fromm, 2004; Häusler et al., 2014) and was especially highlighted following the discovery of the interesting role of GABA in pollen tube growth and guidance (Palanivelu et al., 2003) and by identifying genes that encode putative receptors that possess domains, which are structurally homologous to mammalian $\mathrm{GABA}_{B}$ receptors (Lacombe et al., 2001). Also, the role of GABA in regulating expression of several genes was reported: ACC-synthase (Kathiresan et al., 1997), arginine-decarboxylase (Turano et al., 1997), 14-3-3 (Lancien and Roberts, 2006), and genes encoding secreted and cell wall associated proteins (Renault et al., 2011). Consistent with a role in ACC-Synthase regulation, exogenously applied GABA was shown to induce ethylene emission in Stellaria longipes and sunflower (Kathiresan et al., 1997, 1998). Nevertheless, in our opinion, the most compelling evidence suggesting that GABA is a signaling molecule in plants is the detection of Quantum dot (QD)-mediated GABA binding sites on the surface of plant pollen and somatic protoplasts, implying the existence of GABA receptors. Importantly, the binding of the QD-GABA probes caused transient elevation in intracellular
$\mathrm{Ca}^{2+}$ levels (Yu et al., 2006; Figure 1), which is known to induce signaling pathways in plants (Galon et al., 2010; Batistič and Kudla, 2012; Fromm and Finkler, 2015). Notably, it was recently shown that this increase in $\mathrm{Ca}^{2+}$ levels is the result of the modulation of $\mathrm{Ca}^{2+}$-permeable channels to enable proper pollen tube growth, further supporting the suggestion that the requirement for a GABA gradient along pollen tube is related to its signaling role rather than to a metabolic one (Yu et al., 2014).

Furthermore, a role for GABA as a signal between plants and bacteria is already well established (Shelp et al., 2006). GABA that accumulates in wounded plant tissues restricts quorum sensing of Agrobacterium tumefaciens by regulating expression of the bacterial attKLM operon (Chevrot et al., 2006). It was shown that plant GAD is responsible for the accumulation of the GABA signal that is transported into the bacteria via the bacterial Bra $\mathrm{ABC}$ transporter. Interestingly, plants with an ectopically functional GAD, which lacks the $\mathrm{Ca}^{2+} /$ Calmodulin $\left(\mathrm{Ca}^{2+} / \mathrm{CaM}\right)$ binding domain, exhibited increased resistance to Agrobacterium infection (Chevrot et al., 2006). Increased GABA shunt activity was more recently also associated with tomato resistance to Botrytis cinerea (Seifi et al., 2013). In pepper (Capsicum annuum), the Xanthomonas campestris pv. vesicatoria effector, AvrBsT, induces hypersensitive cell death. Investigation of this effector revealed that it interacts with a pepper arginine decarboxylase $(\mathrm{CaADC} 1)$ and their joint expression is accompanied by polyamine, nitric oxide and hydrogen peroxide bursts. Treatment of pepper with GABA significantly reduced growth of avirulent Xanthomonas campestris, suggesting a role for GABA in cell death promotion (Kim et al., 2013). This is consistent with an older report exhibiting GABA as a modulator of soybean (Glycine max) arginine decarboxylase, ultimately affecting polyamine biosynthesis (Turano et al., 1997). The association of GABA and cell death was also demonstrated in Arabidopsis seeds expressing a constitutively active GAD where up-regulation of cell-death-associated genes was detected. Among the over-represented categories of genes expressed in the hyperaccumulating GABA seeds were those involved in $\mathrm{Ca}^{2+}$. mediated signaling, redox and cysteine proteases (Fait et al., 2011). The over representation of $\mathrm{Ca}^{2+}$-signaling associated genes is intriguing in light of the transient change in $\mathrm{Ca}^{2+}$ levels caused by applying GABA to protoplasts (Yu et al., 2006). Furthermore, mutation in GABA-T (which results in GABA accumulation) was shown also to suppress plant response to E-2-Hexenal, a herbivore and pathogen associated $\mathrm{C}_{6}$-volatile. This volatile was shown to increase GABA levels (Mirabella et al., 2007).

$\gamma$-Aminobutyric acid accumulation also results in the down regulation of genes associated with cell-wall modifications (Renault et al., 2011; Batushansky et al., 2014). Cell wall modification are correlated with developmental changes which are exerted on plants by environmental constraints (Roppolo and Geldner, 2012). Indeed, the association of increased GABA levels with altered plant development was demonstrated extensively. Ectopically active GAD (lacking its $\mathrm{Ca}^{2+} / \mathrm{CaM}$ regulated autoinhibitory domain) in transgenic tobacco results in developmental abnormalities that include shortened and more branched plants. Young developing leaves exhibited a delay in greening and were narrower than normal and the plants lacked 
pollen. Histological analysis revealed shorter cells in the stem cortex parenchyma of these lines, which could in part explain the short plant phenotype (Baum et al., 1996). These observations are consistent with more recent evidence from GABA-T mutants displaying cell elongation defects and dwarfism in Arabidopsis and tomato (Renault et al., 2011; Koike et al., 2013), especially under salt stress (Renault et al., 2013). Immuno-localization of GABA in pine seedlings suggests a role for GABA in vascular development (Molina-Rueda et al., 2015). Moreover, Arabidopsis ssadh mutants are significantly dwarfed, a phenotype that can be rescued by a second mutation in $G A B A-T$, which encodes the enzyme that functions upstream of SSADH in the mitochondrial GABA catabolism process (Ludewig et al., 2008). Interestingly, SSADH was implicated in Arabidopsis patterning along the abaxial/adaxial axis and these patterning defects were recovered in an ssadh/gaba-t double mutant (Toyokura et al., 2011). These authors suggested that it is the SSA intermediate between GABA and succinate that is mediating this patterning process (Toyokura et al., 2011, 2012).

In conclusion, GABA levels can readily be affected by activating plant GAD (which is tightly regulated by $\mathrm{Ca}^{2+} / \mathrm{CaM}$ ), by suppressing its catabolism (through suppression of GABA-T), by exogenous application of GABA or by interrupting the cellular $\mathrm{C}: \mathrm{N}$ balance (through suppressing of primary metabolism related enzymes such as TCAC enzymes). Such changes in GABA levels result in plant responses at the metabolic, transcriptional and developmental levels, which are difficult to explain solely within a metabolic context. Although there is yet no direct evidence for a signaling role of GABA in plants, it's impossible to ignore the numerous evidences that imply the existence of such signaling pathways.

\section{Coupling of GABA Metabolism and Signaling Under Nutrient Starvation}

In order to obtain further insight into natural modulation of GABA levels, we discuss the current knowledge regarding GABA metabolism under plant starvation in comparison to metabolism in starved animals. We suggest that the metabolic and signaling functions of GABA evolved to be functionally entwined.

Metabolic profiling of Arabidopsis mutants impaired in enzymes that are essential for respiration under extended darkinduced $\mathrm{C}$ starvation revealed an increase in the content of several AAs associated with starvation-induced protein degradation (Araújo et al., 2010). On the other hand, the levels of GABA and of the TCAC intermediate, succinate, increased significantly in these mutants although both metabolites are not the product of protein degradation. The authors suggested that an increase in GABA shunt activity produces mitochondrial succinate to maintain respiration in these mutants (Araújo et al., 2010). This was also apparent in a different study that employed metabolic and transcriptional analyses to decipher mechanisms mediating the Arabidopsis response to dark-induced starvation. GABA was once again highlighted as the major non-proteinogenic AA with a tight correlation to succinate levels (Caldana et al., 2011). Notably, at the transcriptional level, starving plants exhibited significant reduced expression of TCAC-associated SCOAS genes in parallel to a significant increase in $S S A D H$ expression, implying an induction of the GABA shunt bypass under these circumstances (Caldana et al., 2011). Though succinate accumulation in starved plants may be explained by its use as an electron donor in the respiratory chain, the accumulation of GABA, if not merely a metabolic side effect, awaits explanation. One possibility is that the accumulation of GABA is a prerequisite for its signaling function. Let's look at an example for such a metabo-signaling coupling of GABA under low energy status in an organism with a well-established signaling role of GABA.

In mice, the brain is responsible for inducing a hunger sensation under low (or no) food availability that will result in a behavioral response of seeking and consuming food (Atasoy et al., 2012; Wu et al., 2012). An interesting report demonstrates how specific neurons (AgRP neurons of the arcuate nucleus) modulate feeding behavior in mice by providing GABAergic input into mice brainstem (the parabrachial nucleus; $\mathrm{PBN}$ ) and how inactivation of GABA biosynthesis (by inactivating murine Gad1) in the arcuate nucleus, or block of $\mathrm{GABA}(\mathrm{A})$ receptors in the $\mathrm{PBN}$, promotes mice anorexia (Wu et al., 2009). This elegantly shows how GABA neurotransmission participates in the maintenance of energy homeostasis of the whole organism (feeding behavior) and how it is directly affected by GABA biosynthesis through the action of Gad1 (Dietrich and Horvath, 2009; Wu et al., 2009).

As autotrophic organisms, the two main aspects of plant "feeding" are photosynthesis and nutrient uptake by the root. GABA is one of few metabolites whose metabolic path is divided between the cytosol and the mitochondrion matrix. The possibility to target mitochondrial metabolism as a means to enhance photosynthesis was already discussed (Nunes-Nesi et al., 2011; Araújo et al., 2014) and shown (Araújo et al., 2011b). Notably, in silico analysis of optimal photosynthesis in cyanobacteria highlighted the importance of the GABA shunt, combined with an incomplete TCAC during autotrophic metabolism (Nogales et al., 2012). Remarkably, some GABA-T isoforms of rice and tomato were shown to localize in plastids (Clark et al., 2009b; Shimajiri et al., 2013b). This suggests a role for GABA or its derivatives in plastid-associated functions. Indeed exogenously applied GABA resulted in increased photosynthesis parameters is muskmelon seedlings, mainly under hypoxia stress (Xia et al., 2011).

Nevertheless, in order to more accurately compare animal feeding with plant "feeding" it is more prudent to refer also to nutrient uptake by plant roots. Two reports suggest a signaling role for GABA in nitrate uptake in Brassica napus roots (Beuve et al., 2004) and more recently in Arabidopsis thaliana (Barbosa et al., 2011). An earlier report described how GABA enhances significantly the growth of Lemna minor plants by increasing mineral consumption. In contrast, isomers of GABA such as 3 -aminobutyric acid and 2-aminobutyric acid inhibited plant growth. Remarkably, GABA mediated promotion of Lemna growth was inhibited by bicuculline and picrotoxin, which are competitive and non-competitive antagonists of GABA receptors in the mammalian central nerve system, respectively. Consistent with these findings, Baclofen, a known GABA agonist in animals, significantly increased GABA mediated promotion of Lemna growth suggesting the existence of GABA receptors in plants that 
participate in nutrient uptake and eventually affect plant growth (Kinnersley and Lin, 2000). Moreover, a role for GABA in the up-regulation of nodule activity was also suggested (Sulieman and Schulze, 2010) followed by evidences for a role of GABA in increasing the efficiency of symbiotic $\mathrm{N}_{2}$ fixation in legumes (Sulieman, 2011). Thus, it seems that GABA levels increase during plant starvation and energetically demanding stresses. Importantly, GABA seems to induce plant responses that may aid in replenishing the energetic supply, very similar to the action of GABA in mammals where it modulates feeding behavior. The already mentioned effect of GABA on exerting cell-elongation arrest may be important in parallel in order to save cellular energy. Thus, the combined GABA associated effects of modulating photosynthesis and nutrient uptake, in parallel to growth arrest, may be pivotal to ensure plant survival under energetically demanding stresses.

\section{Concluding Remarks}

$\gamma$-Aminobutyric acid is a major metabolic component in the interface between $\mathrm{C}$ and $\mathrm{N}$ metabolism. As such, its levels are "sensitive" to the availability of both essential elements, which makes it an excellent sensor for the energetic state of the cell. Thus, GABA seems ideal to serve as a signal that participates in a pathway that "instructs" the organism whether to try and gain more energy, or whether to initiate processes to

\section{References}

Andriamampandry, C., Siffert, J. C., Schmitt, M., Garnier, J. M., Staub, A., Muller, C., et al. (1998). Cloning of a rat brain succinic semialdehyde reductase involved in the synthesis of the neuromodulator $\gamma$-hydroxybutyrate. Biochem. J. 334, 43-50.

Araújo, W. L., Ishizaki, K., Nunes-Nesi, A., Larson, T. R., Tohge, T., Krahnert, I., et al. (2010). Identification of the 2-hydroxyglutarate and isovaleryl-CoA dehydrogenases as alternative electron donors linking lysine catabolism to the electron transport chain of Arabidopsis mitochondria. Plant Cell 22, 1549-1563. doi: $10.1105 /$ tpc. 110.075630

Araújo, W. L., Nunes-Nesi, A., and Fernie, A. (2014). On the role of plant mitochondrial metabolism and its impact on photosynthesis in both optimal and sub-optimal growth conditions. Photosyn. Res. 119, 141-156. doi: 10.1007/s11120-013-9807-4

Araújo, W. L., Nunes-Nesi, A., Nikoloski, Z., Sweetlove, L. J., and Fernie, A. R. (2011a). Metabolic control and regulation of the tricarboxylic acid cycle in photosynthetic and heterotrophic plant tissues. Plant Cell Environ. 35, 1-21. doi: 10.1111/j.1365-3040.2011.02332.x

Araújo, W. L., Nunes-Nesi, A., Osorio, S., Usadel, B. R., Fuentes, D., Nagy, R. K., et al. (2011b). Antisense inhibition of the iron-sulphur subunit of succinate dehydrogenase enhances photosynthesis and growth in tomato via an organic acid-mediated effect on stomatal aperture. Plant Cell 23, 600-627. doi: 10.1105/tpc.110.081224

Araújo, W. L., Nunes-Nesi, A., Trenkamp, S., Bunik, V. I., and Fernie, A. R. (2008). Inhibition of 2-oxoglutarate dehydrogenase in potato tuber suggests the enzyme is limiting for respiration and confirms its importance in nitrogen assimilation. Plant Physiol. 148, 1782-1796. doi: 10.1104/pp.108.126219

Atasoy, D., Betley, J. N., Su, H. H., and Sternson, S. M. (2012). Deconstruction of a neural circuit for hunger. Nature 488, 172-177. doi: 10.1038/nature11270

Barbosa, J. M., Singh, N. K., Cherry, J. H., and Locy, R. D. (2011). Nitrate uptake and utilization is modulated by exogenous $\gamma$-aminobutyric acid in Arabidopsis thaliana seedlings. Plant Physiol. Biochem. 48, 443-450. doi: 10.1016/j.plaphy.2010.01.020 cope with excess energy. Also, it seems that GABA is a major alternative pathway to which $\mathrm{C}$ skeleton is directed depending on the environment, growth stage, and tissue specificity. These reports summarized here suggest that from an evolutionary perspective, GABA metabolism predated signaling, and that mechanistically, GABA metabolism underlies its signaling functions. This is consistent with a work that integrated metabolomics with transcript and enzyme activity profiling of plants undergoing diurnal cycles. The authors concluded that “...correlation between metabolites and transcripts are due to regulation of gene expression by metabolites, rather than metabolites being changed as a consequence of a change in gene expression" (Gibon et al., 2006). Future research should shed light on the manner by which physiological increase in GABA levels, either by GAD induction, repression of catabolism or increased flux in the direction of the GABA shunt, affect plant resilience and development. Identification of the cell-surface localized GABA receptors, as well as identifying components that participate in GABA-mediated gene control is essential to this end.

\section{Acknowledgments}

We thank Dr. Oren Tzfadia (VIB Ghent, Belgium) for critical reading of the manuscript and fruitful input. We apologize to colleagues whose work we could not cite due to space limitations.

Batistič, O., and Kudla, J. (2012). Analysis of calcium signaling pathways in plants. Biochim. Biophys. Acta 1820, 1283-1293. doi: 10.1016/j.bbagen.2011.10.012

Batushansky, A., Kirma, M., Grillich, N., Toubiana, D., Pham, P. A., Balbo, I., et al. (2014). Combined transcriptomics and metabolomics of Arabidopsis thaliana seedlings exposed to exogenous GABA suggest its role in plants is predominantly metabolic. Mol. Plant 7, 1065-1068. doi: 10.1093/mp/ ssu017

Baum, G., Chen, Y., Arazi, T., Takatsuji, H., and Fromm, H. (1993). A plant glutamate decarboxylase containing a calmodulin binding domain. Cloning, sequence, and functional analysis. J. Biol. Chem. 268, 19610-19617

Baum, G., Lev-Yadun, S., Fridmann, Y., Arazi, T., Katsnelson, H., Zik, M., et al. (1996). Calmodulin binding to glutamate decarboxylase is required for regulation of glutamate and GABA metabolism and normal development in plants. EMBO J. 15, 2988-2996

Beuve, N., Rispail, N., Laine, P., Cliquet, J. B., Ourry, A., and Le Deunff, E. (2004). Putative role of $\gamma$-aminobutyric acid (GABA) as a long-distance signal in up-regulation of nitrate uptake in Brassica napus L. Plant Cell Environ. 27, 1035-1046. doi: 10.1111/j.1365-3040.2004.01208.x

Bouché, N., Fait, A., Bouchez, D., Moller, S. G., and Fromm, H. (2003a). Mitochondrial succinic-semialdehyde dehydrogenase of the $\gamma$-aminobutyrate shunt is required to restrict levels of reactive oxygen intermediates in plants. Proc. Natl. Acad. Sci. U.S.A. 100, 6843-6848. doi: 10.1073/pnas. 1037532100

Bouché, N., Lacombe, B., and Fromm, H. (2003b). GABA signaling: a conserved and ubiquitous mechanism. Trends Cell Biol. 13, 607-610. doi: 10.1016/j.tcb.2003.10.001

Bouché, N., and Fromm, H. (2004). GABA in plants: just a metabolite? Trends Plant Sci. 9, 110-115. doi: 10.1016/j.tplants.2004.01.006

Bown, A. W., and Shelp, B. J. (1997). The metabolism and functions of $\gamma$ aminobutyric acid. Plant Physiol. 115, 1-5.

Breitkreuz, K. E., Allan, W. L., Van Cauwenberghe, O. R., Jakobs, C., Talibi, D., Andre, B., et al. (2003). A novel $\gamma$-hydroxybutyrate dehydrogenase. J. Biol. Chem. 278, 41552-41556. doi: 10.1074/jbc.M305717200

Caldana, C., Degenkolbe, T., Cuadros-Inostroza, A., Klie, S., Sulpice, R., Leisse, A., et al. (2011). High-density kinetic analysis of the metabolomic and 
transcriptomic response of Arabidopsis to eight environmental conditions. Plant J. 67, 869-884. doi: 10.1111/j.1365-313X.2011.04640.x

Chevrot, R., Rosen, R., Haudecoeur, E., Cirou, A., Shelp, B. J., Ron, E., et al. (2006). GABA controls the level of quorum-sensing signal in Agrobacterium tumefaciens. Proc. Natl. Acad. Sci. U.S.A. 103, 7460-7464. doi: 10.1073/pnas.0600313103

Clark, S. M., Di Leo, R., Dhanoa, P. K., Van Cauwenberghe, O. R., Mullen, R. T., and Shelp, B. J. (2009a). Biochemical characterization, mitochondrial localization, expression, and potential functions for an Arabidopsis $\gamma$-aminobutyrate transaminase that utilizes both pyruvate and glyoxylate. J. Exp. Bot. 60, 1743-1757. doi: 10.1093/jxb/erp044

Clark, S. M., Di Leo, R., Van Cauwenberghe, O. R., Mullen, R. T., and Shelp, B. J. (2009b). Subcellular localization and expression of multiple tomato $\gamma$ aminobutyrate transaminases that utilize both pyruvate and glyoxylate. J. Exp. Bot. 60, 3255-3267. doi: 10.1093/jxb/erp161

Deleu, C., Faes, P., Niogret, M.-F. O., and Bouchereau, A. (2013). Effects of the inhibitor of the $\gamma$-aminobutyrate-transaminase, vinyl- $\gamma$-aminobutyrate, on development and nitrogen metabolism in Brassica napus seedlings. Plant Physiol. Biochem. 64, 60-69. doi: 10.1016/j.plaphy.2012.12.007

Dietrich, M. O., and Horvath, T. L. (2009). GABA keeps up an appetite for life. Cell 137, 1177-1179. doi: 10.1016/j.cell.2009.06.002

Fait, A., Fromm, H., Walter, D., Galili, G., and Fernie, A. R. (2008). Highway or byway: the metabolic role of the GABA shunt in plants. Trends Plant Sci. 13, 14-19. doi: 10.1016/j.tplants.2007.10.005

Fait, A., Nesi, A. N., Angelovici, R., Lehmann, M., Pham, P. A., Song, L., et al. (2011). Targeted enhancement of glutamate-to- $\gamma$-aminobutyrate conversion in Arabidopsis seeds affects carbon-nitrogen balance and storage reserves in a development-dependent manner. Plant Physiol. 157, 1026-1042. doi: 10.1104/pp.111.179986

Fromm, H., and Finkler, A. (2015). Repression and de-repression of gene expression in the plant immune response: the complexity of modulation by $\mathrm{Ca}^{2+}$ and calmodulin. Mol. Plant 8, 671-673. doi: 10.1016/j.molp.2015.01.019

Galon, Y., Finkler, A., and Fromm, H. (2010). Calcium-regulated transcription in plants. Mol. Plant 3, 653-669. doi: 10.1093/mp/ssq019

Gibon, Y., Usadel, B., Blaesing, O., Kamlage, B., Hoehne, M., Trethewey, R., et al. (2006). Integration of metabolite with transcript and enzyme activity profiling during diurnal cycles in Arabidopsis rosettes. Genome Biol. 7, 1-23. doi: 10.1186/gb-2006-7-8-r76

Häusler, R. E., Ludewig, F., and Krueger, S. (2014). Amino acids-a life between metabolism and signaling. Plant Sci. 229, 225-237. doi: 10.1016/j.plantsci.2014.09.011

Kathiresan, A., Miranda, J., Chinnappa, C. C., and Reid, D. M. (1998). $\gamma$ aminobutyric acid promotes stem elongation in Stellaria longipes: the role of ethylene. Plant Growth Regul. 26, 131-137. doi: 10.1023/A:1006107815064

Kathiresan, A., Tung, P., Chinnappa, C. C., and Reid, D. M. (1997). $\gamma$-aminobutyric acid stimulates ethylene biosynthesis in sunflower. Plant Physiol. 115, 129-135.

Kim, N. H., Kim, B. S., and Hwang, B. K. (2013). Pepper arginine decarboxylase is required for polyamine and $\gamma$-aminobutyric acid signaling in cell death and defense response. Plant Physiol. 162, 2067-2083. doi: 10.1104/pp.113.217372

Kinnersley, A. M., and Lin, F. (2000). Receptor modifiers indicate that 4aminobutyric acid (GABA) is a potential modulator of ion transport in plants. Plant Growth Regul. 32, 65-76. doi: 10.1023/a:1006305120202

Kinnersley, A. M., and Turano, F. J. (2000). $\gamma$ aminobutyric acid (GABA) and plant responses to stress. Crit. Rev. Plant Sci. 19, 479-509. doi: 10.1080/07352680091139277

Koike, S., Matsukura, C., Takayama, M., Asamizu, E., and Ezura, H. (2013). Suppression of $\gamma$-aminobutyric acid (GABA) transaminases induces prominent GABA accumulation, dwarfism and infertility in the tomato (Solanum lycopersicum L.). Plant Cell Physiol. 54, 793-807. doi: 10.1093/pcp/pct035

Kumar, S., Punekar, N. S., Satyanarayan, V., and Venkatesh, K. V. (2000). Metabolic fate of glutamate and evaluation of flux through the 4-aminobutyrate (GABA) shunt in Aspergillus niger. Biotechnol. Bioeng. 67, 575-584. doi: 10.1002/(SICI)1097-0290(20000305)67:5<575::AID-BIT8>3.0.CO;2-L

Lacombe, B., Becker, D., Hedrich, R., Desalle, R., Hollmann, M., Kwak, J. M., et al. (2001). The identity of plant glutamate receptors. Science 292, 1486-1487. doi: $10.1126 /$ science.292.5521.1486b

Lancien, M., and Roberts, M. R. (2006). Regulation of Arabidopsis thaliana 14-3-3 gene expression by $\gamma$-aminobutyric acid. Plant Cell Environ. 29, 1430-1436. doi: 10.1111/j.1365-3040.2006.01526.x
Ludewig, F., Hüser, A., Fromm, H., Beauclair, L., and Bouché, N. (2008). Mutants of GABA transaminase (POP2) suppress the severe phenotype of succinic semialdehyde dehydrogenase (ssadh) Mutants in Arabidopsis. PLoS ONE 3:e3383. doi: 10.1371/journal.pone.0003383

Metzer, E., and Halpern, Y. S. (1990). In vivo cloning and characterization of the gabCTDP gene cluster of Escherichia coli K-12. J. Bacteriol. 172, 3250-3256.

Meyer, A., Eskandari, S., Grallath, S., and Rentsch, D. (2006). AtGAT1, a high affinity transporter for $\gamma$-aminobutyric acid in Arabidopsis thaliana. J. Biol. Chem. 281, 7197-7204. doi: 10.1074/jbc.M510766200

Michaeli, S., Fait, A., Lagor, K., Nunes-Nesi, A., Grillich, N., Yellin, A., et al. (2011). A mitochondrial GABA permease connects the GABA shunt and the TCA cycle, and is essential for normal carbon metabolism. Plant J. 67, 485-498. doi: 10.1111/j.1365-313X.2011.04612.x

Mirabella, R., Rauwerda, H., Struys, E. A., Jakobs, C., Triantaphylides, C., Haring, M. A., et al. (2007). The Arabidopsis her1 mutant implicates GABA in E-2-hexenal responsiveness. Plant J. 53, 197-213. doi: 10.1111/j.1365-313X.2007.03323.x

Molina-Rueda, J. S., Pascual, M. N., Pissarra, J., and Gallardo, F. (2015). A putative role for $\gamma$-aminobutyric acid (GABA) in vascular development in pine seedlings. Planta 241, 257-267. doi: 10.1007/s00425-014-2157-4

Nogales, J., Gudmundsson, S., Knight, E. M., Palsson, B. O., and Thiele, I. (2012). Detailing the optimality of photosynthesis in cyanobacteria through systems biology analysis. Proc. Natl. Acad. Sci. U.S.A. 109, 2678-2683. doi: 10.1073/pnas.1117907109

Nunes-Nesi, A., Araújo, W. L., and Fernie, A. R. (2011). Targeting mitochondrial metabolism and machinery as a means to enhance photosynthesis. Plant Physiol. 155, 101-107. doi: 10.1104/pp.110.163816

Palanivelu, R., Brass, L., Edlund, A. F., and Preuss, D. (2003). Pollen tube growth and guidance is regulated by POP2, an Arabidopsis gene that controls GABA levels. Cell 114, 47-59. doi: 10.1016/S0092-8674(03)00479-3

Renault, H. (2013). Fiat lux! Phylogeny and bioinformatics shed light on GABA functions in plants. Plant Signal. Behav. 8, e24274. doi: 10.4161/psb.24274

Renault, H., El Amrani, A., Berger, A., Mouille, G., Soubigou-Taconnat, L., Bouchereau, A., et al. (2013). $\gamma$-aminobutyric acid transaminase deficiency impairs central carbon metabolism and leads to cell wall defects during salt stress in Arabidopsis roots. Plant Cell Environ. 36, 1009-1018. doi: 10.1111/pce.12033

Renault, H., El Amrani, A., Palanivelu, R., Updegraff, E. P., Yu, A. S., Renou, J.-P., et al. (2011). GABA accumulation causes cell elongation defects and a decrease in expression of genes encoding secreted and cell wall-related proteins in Arabidopsis thaliana. Plant Cell Physiol. 52, 894-908. doi: 10.1093/pcp/ pcr041

Roberts, E., Eidelberg, E., Carl, C. P., and John, R. S. (1960). Metabolic and neurophysiological roles of $\gamma$-aminobutyric acid. Int. Rev. Neurobiol. 2, 279-332.

Roberts, E., and Frankel, S. (1950). $\gamma$-aminobutyric acid in brain: its formation from glutamic-acid. J. Biol. Chem. 187, 55-63.

Roppolo, D., and Geldner, N. (2012). Membrane and walls: who is master, who is servant? Curr. Opin. Plant Biol. 15, 608-617. doi: 10.1016/j.pbi.2012.09.009

Saito, N., Robert, M., Kochi, H., Matsuo, G., Kakazu, Y., Soga, T., et al. (2009). Metabolite profiling reveals YihU as a novel hydroxybutyrate dehydrogenase for alternative succinic semialdehyde metabolism in Escherichia coli. J. Biol. Chem. 284, 16442-16451. doi: 10.1074/jbc.M109.002089

Seifi, H. S., Curvers, K., De Vleesschauwer, D., Delaere, I., Aziz, A., and Höfte, M. (2013). Concurrent overactivation of the cytosolic glutamine synthetase and the GABA shunt in the ABA-deficient sitiens mutant of tomato leads to resistance against Botrytis cinerea. New Phytol. 199, 490-504. doi: 10.1111/nph.12283

Shelp, B. J., Bown, A. W., and Faure, D. (2006). Extracellular $\gamma$-aminobutyrate mediates communication between plants and other organisms. Plant Physiol. 142, 1350-1352. doi: 10.1104/pp.106.088955

Shelp, B. J., Bown, A. W., and Mclean, M. D. (1999). Metabolism and functions of $\gamma$-aminobutyric acid. Trends Plant Sci. 4, 446-452. doi: 10.1016/S13601385(99)01486-7

Shelp, B. J., Bozzo, G. G., Trobacher, C. P., Zarei, A., Deyman, K. L., and Brikis, C. J. (2012a). Hypothesis/review: contribution of putrescine to 4-aminobutyrate (GABA) production in response to abiotic stress. Plant Sci. 193-194, 130-135. doi: 10.1016/j.plantsci.2012.06.001

Shelp, B. J., Mullen, R. T., and Waller, J. C. (2012b). Compartmentation of GABA metabolism raises intriguing questions. Trends Plant Sci. 17, 57-59. doi: 10.1016/j.tplants.2011.12.006

Shimajiri, Y., Oonishi, T., Ozaki, K., Kainou, K., and Akama, K. (2013a). Genetic manipulation of the $\gamma$-aminobutyric acid (GABA) shunt in rice: 
overexpression of truncated glutamate decarboxylase (GAD2) and knockdown of $\gamma$-aminobutyric acid transaminase (GABA-T) lead to sustained and high levels of GABA accumulation in rice kernels. Plant Biotechnol. J. 11, 594-604. doi: $10.1111 /$ pbi. 12050

Shimajiri, Y., Ozaki, K., Kainou, K., and Akama, K. (2013b). Differential subcellular localization, enzymatic properties and expression patterns of $\gamma$-aminobutyric acid transaminases (GABA-Ts) in rice (Oryza sativa). J. Plant Physiol. 170, 196-201. doi: 10.1016/j.jplph.2012.09.007

Signorelli, S., Dans, P. D., Coitiño, E. L., Borsani, O., and Monza, J. (2015). Connecting proline and $\gamma$-aminobutyric acid in stressed plants through non-enzymatic reactions. PLoS ONE 10:e0115349. doi: 10.1371/journal.pone.0115349

Snowden, C. J., Thomas, B., Baxter, C. J., Smith, J. A. C., and Sweetlove, L. J. (2015). A tonoplast Glu/Asp/GABA exchanger that affects tomato fruit amino acid composition. Plant J. 81, 651-660. doi: 10.1111/tpj.12766

Steward, F. C., Thompson, J. F., and Dent, C. E. (1949). $\gamma$-aminobutyric acid: a constituent of the potato tuber? Science 110, 439-440.

Studart-Guimaraes, C., Fait, A., Nunes-Nesi, A., Carrari, F., Usadel, B., and Fernie, A. R. (2007). Reduced expression of succinyl-coenzyme A ligase can be compensated for by up-regulation of the $\gamma$-aminobutyrate shunt in illuminated tomato leaves. Plant Physiol. 145, 626-639. doi: 10.1104/pp.107.103101

Sulieman, S. (2011). Does GABA increase the efficiency of symbiotic $\mathrm{N}_{2}$ fixation in legumes? Plant Signal. Behav. 6, 32-36. doi: 10.4161/psb.6.1.14318

Sulieman, S., and Schulze, J. (2010). Phloem-derived $\gamma$-aminobutyric acid (GABA) is involved in upregulating nodule $\mathrm{N}_{2}$ fixation efficiency in the model legume Medicago truncatula. Plant Cell Environ. 33, 2162-2172. doi: 10.1111/j.13653040.2010.02214.x

Sweetlove, L. J., Beard, K. F. M., Nunes-Nesi, A., Fernie, A. R., and Ratcliffe, R. G. (2010). Not just a circle: flux modes in the plant TCA cycle. Trends Plant Sci. 15, 462-470. doi: 10.1016/j.tplants.2010.05.006

Tcherkez, G., Mahé, A., Gauthier, P., Mauve, C., Gout, E., Bligny, R., et al. (2009). In folio respiratory fluxomics revealed by $13 \mathrm{C}$ isotopic labeling and $\mathrm{H} / \mathrm{D}$ isotope effects highlight the noncyclic nature of the tricarboxylic acid "cycle" in illuminated leaves. Plant Physiol. 151, 620-630. doi: 10.1104/pp.109. 142976

Tillakaratne, N. J. K., Medina-Kauwe, L., and Gibson, K. M. (1995). $\gamma$-aminobutyric acid (GABA) metabolism in mammalian neural and nonneural tissues. Comp. Biochem. Physiol. A Physiol. 112, 247-263.

Tomita, H., Yokooji, Y., Ishibashi, T., Imanaka, T., and Atomi, H. (2014). An archaeal glutamate decarboxylase homolog functions as an aspartate decarboxylase and is involved in $\beta$-alanine and coenzyme A biosynthesis. $J$. Bacteriol. 196, 1222-1230. doi: 10.1128/JB.01327-3

Toyokura, K., Hayashi, M., Nishimura, M., and Okada, K. (2012). Adaxial-abaxial patterning: a novel function of the GABA shunt. Plant Signal. Behav. 7, 705-707. doi: $10.4161 /$ psb.20346

Toyokura, K., Watanabe, K., Oiwaka, A., Kusano, M., Tameshige, T., Tatematsu, K., et al. (2011). Succinic semialdehyde dehydrogenase is involved in the robust patterning of Arabidopsis leaves along the adaxial-abaxial axis. Plant Cell Physiol. 52, 1340-1353. doi: 10.1093/pcp/pcr079

Turano, F. J., Kramer, G. F., and Wang, C. Y. (1997). The effect of methionine, ethylene, and polyamine catabolic intermediates on polyamine accumulation in detached soybean leaves. Physiol. Plant. 101, 510-518. doi: 10.1111/j.13993054.1997.tb01031.x

Wu, Q., Boyle, M. P., and Palmiter, R. D. (2009). Loss of GABAergic signaling by AgRP neurons to the parabrachial nucleus leads to starvation. Cell 137, 1225-1234. doi: 10.1016/j.cell.2009.04.022

Wu, Q., Clark, M. S., and Palmiter, R. D. (2012). Deciphering a neuronal circuit that mediates appetite. Nature 483, 594-597. doi: 10.1038/nature10899

Xia, Q.-P., Gao, H.-B., and Li, J.-R. (2011). Effects of $\gamma$-aminobutyric acid on the photosynthesis and chlorophyll fluorescence parameters of muskmelon seedlings under hypoxia stress. Chin. J. Appl. Ecol. 22, 999-1006.

Yu, G.-H., Zou, J., Feng, J., Peng, X. B., Wu, J.-Y., Wu, Y.-L., et al. (2014). Exogenous $\gamma$-aminobutyric acid (GABA) affects pollen tube growth via modulating putative $\mathrm{Ca}^{2+}$-permeable membrane channels and is coupled to negative regulation on glutamate decarboxylase. J. Exp. Bot. 65, 3235-3248. doi: 10.1093/jxb/ eru171

Yu, G., Liang, J., He, Z., and Sun, M. (2006). Quantum dot-mediated detection of $\gamma$-aminobutyric acid binding sites on the surface of living pollen protoplasts in tobacco. Chem. Biol. 13, 723-731. doi: 10.1016/j.chembiol.2006.05.007

Conflict of Interest Statement: The authors declare that the research was conducted in the absence of any commercial or financial relationships that could be construed as a potential conflict of interest.

Copyright (c) 2015 Michaeli and Fromm. This is an open-access article distributed under the terms of the Creative Commons Attribution License (CC BY). The use, distribution or reproduction in other forums is permitted, provided the original author(s) or licensor are credited and that the original publication in this journal is cited, in accordance with accepted academic practice. No use, distribution or reproduction is permitted which does not comply with these terms 